\title{
Pseudoxanthoma elasticum: report of two cases
}

\author{
Gabriela Franco Marques ${ }^{1}$ \\ Ana Paula Cota Pinto Coelho ${ }^{1}$ \\ Josmar Sabage ${ }^{1}$
}

\author{
Sadamitsu Nakandakari ${ }^{1}$ \\ Maria Helena Mazzi Freire Nigro ${ }^{1}$
}

DOI: http://dx.doi.org/10.1590/abd1806-4841.20143144

\begin{abstract}
Pseudoxanthoma elasticum is a rare inherited multisystem disorder that is characterized by a pathological mineralization of the elastic connective tissue, which involves predominantly the skin, eyes and cardiovascular system. Its cause lies on mutations in the ABCC6 gene, which lead to reduction or absence of the transmembrane transport ADP dependent protein (MRP6), causing an accumulation of extracellular material and subsequent deposition of calcium and other minerals in the elastic tissue. The authors report two cases of pseudoxanthoma elasticum, emphasizing its major clinical features and the importance of early diagnosis of the disorder, aiming for adequate therapeutic management of associated complications.
\end{abstract}

Keywords: Connective tissue; Elastic tissue; Pseudoxanthoma elasticum

\section{INTRODUCTION}

Pseudoxanthoma elasticum is a rare inherited multisystem disorder characterized by pathological calcification of the elastic connective tissue, involving predominantly the skin, eyes (retina Bruch's membrane) and cardiovascular system. The precise prevalence of this illness is unknown; however, a variable involvement between 1:25,000-100,000 inhabitants worldwide is estimated, with slight prevalence of females. ${ }^{1,2}$

The first clinical description of the disease was done in 1881 by Rigal, and in 1896 Darier adopted the term pseudoxanthoma elasticum after observing typical dermal histopathological alterations of the process. Ocular involvement was observed for the first time in 1929 by Grönblad and Strandberg, while early atheromatosis, the last component of the disease, was described in 1944, occasion in which Carlbord reported calcification of vessel walls in 29 patients with pseudoxanthoma elasticum. ${ }^{1}$

The authors report two cases of pseudoxanthoma elasticum, emphasizing its main clinical aspects and highlighting the importance of early diagnosis of the disease for adequate therapeutical management of associated complications.

\section{CASE REPORT}

\section{Case 1}

Female patient, 48 years old, white, reported the onset of yellowish asymptomatic micropapules in the cervical region five years ago, which later progressed to the axillae and cubital fossae. In her personal records, a past history of arterial hypertension was noticed. The patient denied similar cases in her family. At the dermatological examination, coalescent yellowish papules forming plaques distributed symmetrically in the cervical region, axillas and cubital fossae (Figure 1) were observed. The anatomopathological examination made evident calcified, distorted and fragmented elastic fibers in the dermis, compatible with the diagnosis of pseudoxanthoma elasticum (Figure 2). Cardiological evaluation did not show changes (normal electrocardiogram and echocardiogram). Right ophthalmoscopy identified the presence of angioid streaks, confirmed by retinography and angiography (Figure 3).

\section{Case 2}

Female patient, 55 years old, white, reported the onset of yellowish papules, initially in the cervical region, with progression to the cubital and popliteal

Financial funding: None

Instituto Lauro de Souza Lima (ILSL) - Bauru (SP), Brazil. 


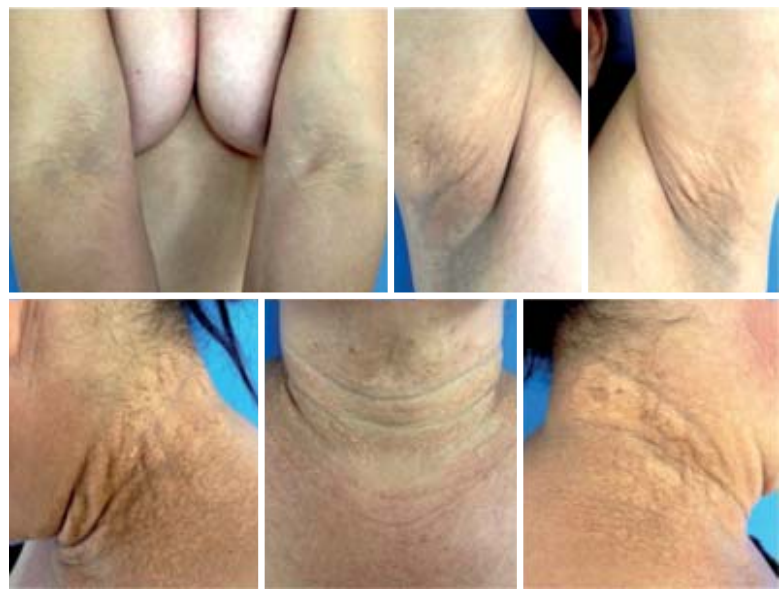

FIGURE 1: Dermatological examination: Irregular skin surface of inelastic consistency, presenting plaques constituted of symmetric small yellowish papules located in the cervical region and flexural areas

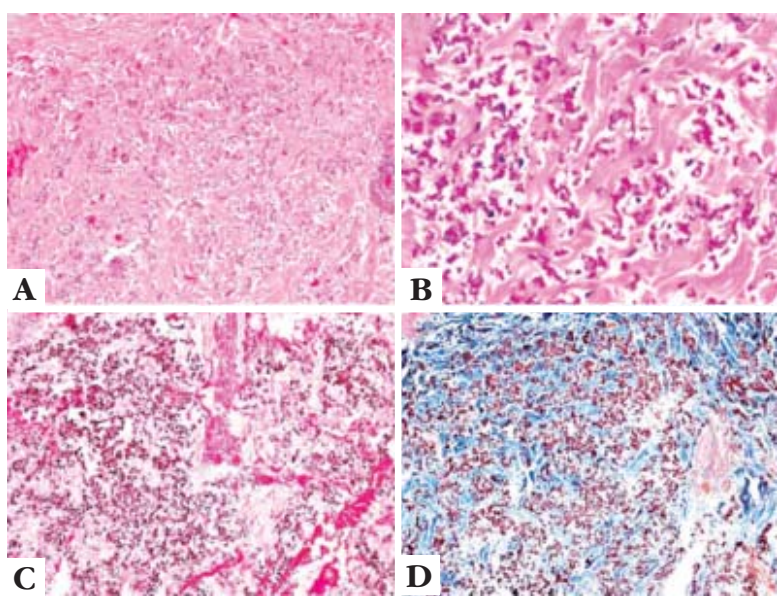

FIGURE 2: Anatomopathological examination: Augmented, fragmented and calcified elastic fibers in the deep dermis, visible under hematoxylin-eosin staining (A and $\mathbf{B})$, and made evident after specific Verhoeff staining for elastic tissue (C) and Calleja (D)
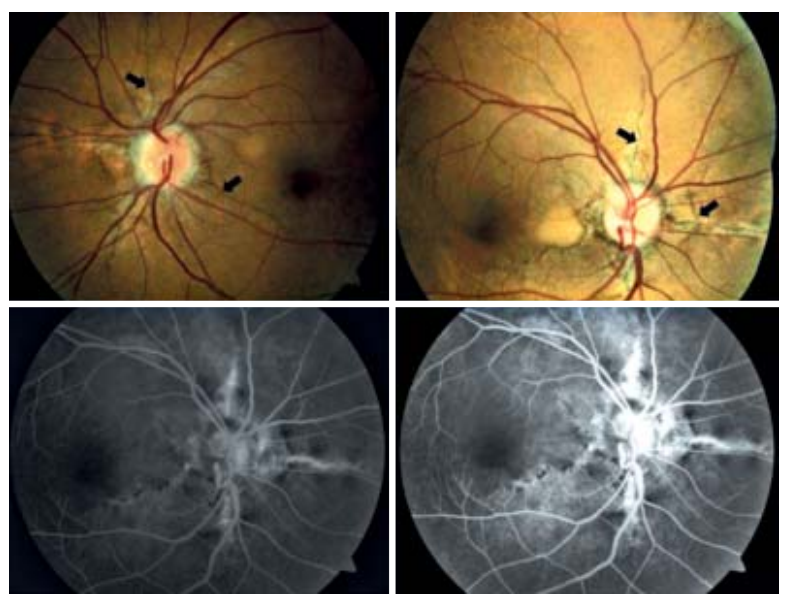

FIGURE 3: Presence of angioid streaks in retinography (arrows), which are hyperfluorescent to fluorescein angiography fossae, inguinal and periumbilical areas. The lesions started during infancy and were asymptomatic. The patient did not present underlying diseases and denied familial cases of the same malady. At the dermatological examination grouped yellowish papules were visualized, forming plaques in all of the cervical region, cubital fossae, right popliteal fossa, bilateral and periumbilical inguinal region (Figure 4). The histological examination revealed calcification and fragmentation of elastic fibers in the middle and deep dermal layers, confirming the diagnosis of pseudoxanthoma elasticum (Figure 5). Right ophthalmoscopy, retinography and angiography revealed angioid streaks (Figure 6). Cardiovascular evaluation did not identify changes and the electrocardiogram and echocardiogram were normal.

\section{DISCUSSION}

Pseudoxanthoma elasticum is a hereditary disease of the elastic connective tissue with an autosomal dominant inheritance pattern in $90 \%$ of the cases, or autosomal recessive. It is caused by a mutation in gene ABCC6 located in the short arm of chromosome 16 , responsible for coding a transmembrane transport ADP dependent protein (MRP6), expressed predomi-

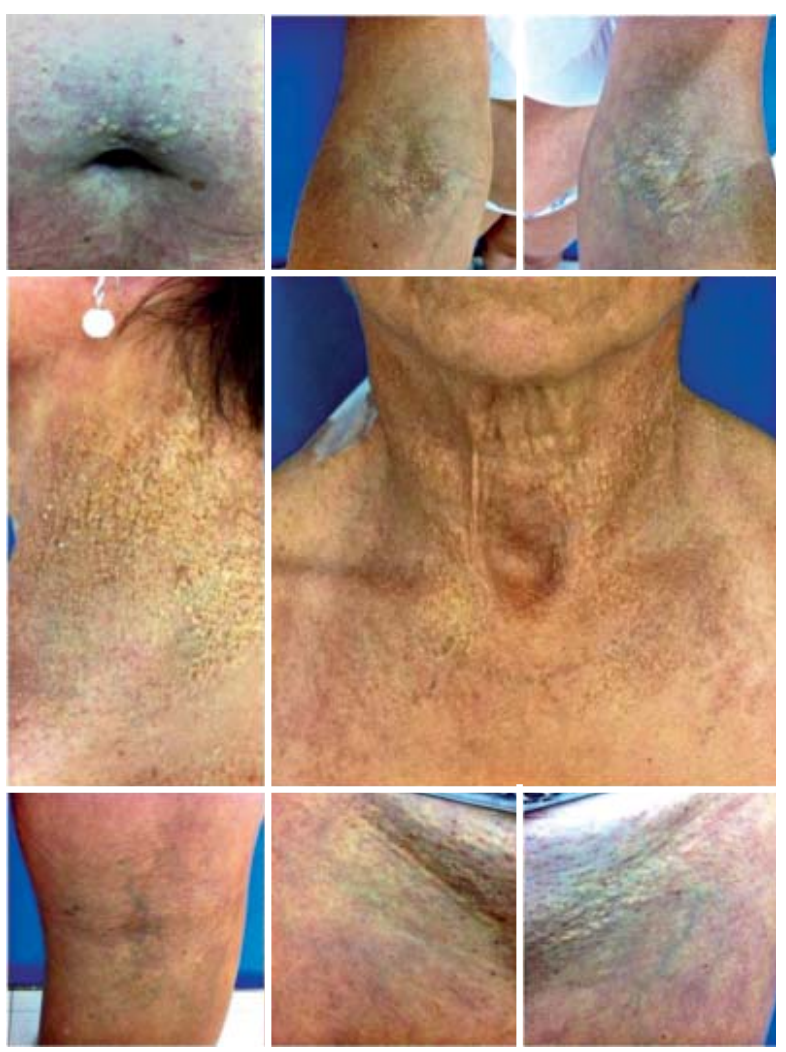

FIGURE 4: Dermatological examination: confluent yellowish small papules symmetrically distributed in the neck, periumbilical region and flexural areas 


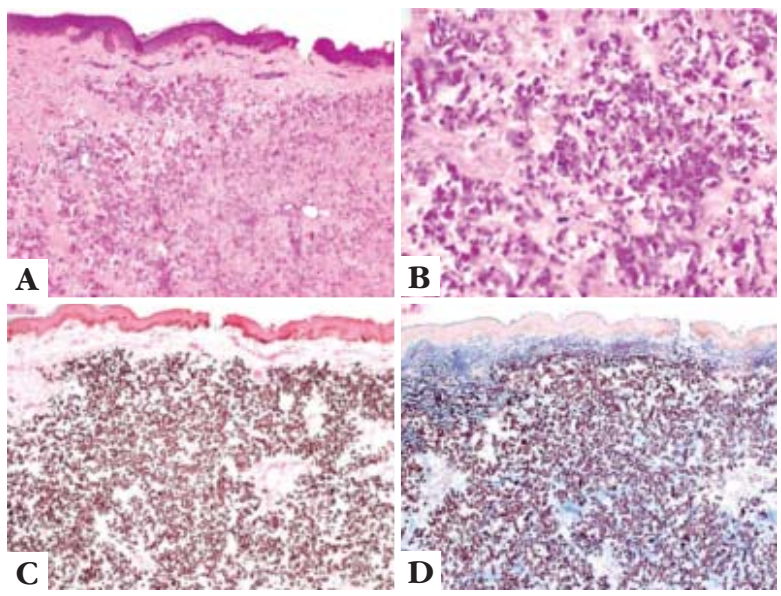

FIGURE 5: Anatomopathological examination: Presence of numerous distorted and fragmented elastic fibers in the reticular and deep dermis under hematoxylin-eosin staining (A and B), Verhoeff (C) and Calleja (D)
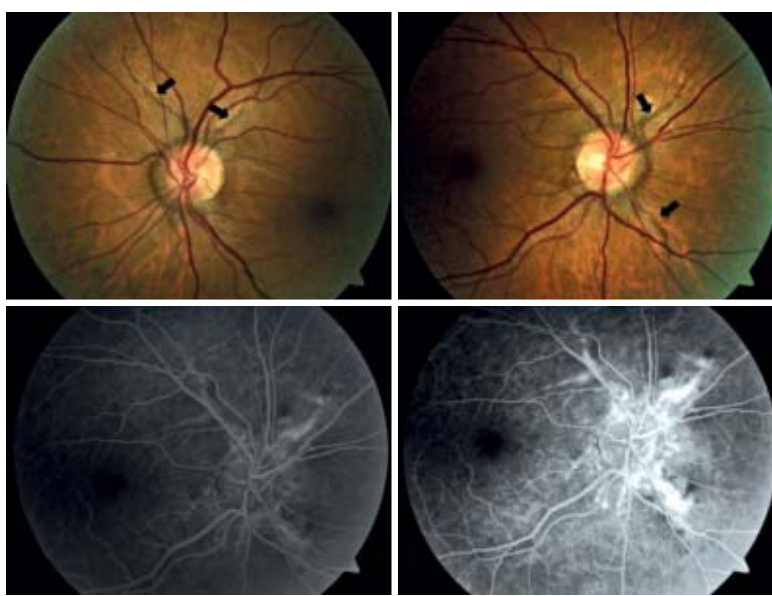

FIGURE 6: Angioid streaks visualized in retinography (arrows) and highlighted in the fluorescein angiography

nantly in the liver and kidneys, and found in low levels in the tissues involved by pseudoxanthoma elasticum. The mutation in gene ABCC6 causes diminishing or absence of this protein and subsequent accumulation of substances with high affinity for the elastic tissue, resulting in calcium deposition and distortion and fragmentation of the elastic fibers. ${ }^{1,3,4}$

Clinical manifestation occur in skin, eyes, oral mucosa, gastrointestinal tract and in the arteries. Cutaneous alterations are the most frequent and are characterized by yellowish asymptomatic papules of 1-3 $\mathrm{mm}$ in diameter, symmetrically distributed in the neck and flexural areas, especially the axillae. Mucosal lesions of similar aspect can be observed in the oral, genital and gastrointestinal mucosae..$^{1,2,3,5}$
The main ocular manifestation consists in the presence of angioid streaks visualized by ophthalmoscopy, which represent the calcium deposit in the retina Bruch's membrane and may lead to the rupture of vessels, with subsequent neovascularization that is associated with retinal hemorrhages and may lead to progressive loss of visual acuity. The cases of ocular involvement must be monitored by periodical fluorescein angiography and ophthalmoscopy.,

In the cardiovascular system the calcification of artery walls of small and medium caliber is observed, which results in early atheromatosis. It can present itself through gastrointestinal hemorrhages, hypertension, acute myocardial infarction, cerebrovascular accident and peripheral arterial occlusion. ${ }^{1,27,8}$

The diagnosis is clinical, associated with anatomopathological examination, which is characteristic and reveals fragmented and distorted elastic fibers in the reticular and deep dermis. These changes are more evident in the Verhoeff, Van Giesson and Calleja stains, specific for the elastic tissue. The calcification of fibers can be clearly identified in stains for calcium, as the Von Kossa. ${ }^{1,2}$

To this day, there is no specific treatment and the therapeutical management is based in prevention, tracking and monitoring of complications associated with the disease. Complementary exams such as blood count, lipid profile, echocardiogram, and ophthalmologic monitoring should be made whenever necessary. The diet supplemented with magnesium and vitamin $\mathrm{K}$ may extend the progression of the disease and improve the quality of life of the patients. Surgery for aesthetic improvement of cutaneous lesions is not routinely performed due to the risk of complications with formation of keloids, dehiscence and extrusion of calcium particles through the surgical wound. ${ }^{9,10}$

The reported cases presented typical clinical manifestations of pseudoxanthoma elasticum, and the diagnosis was confirmed after anatomopathological examination. In the two cases there was ocular involvement confirmed by fluorescein angiography, which revealed the presence of hyperfluorescent angioid streaks arising from changes to retina Bruch's membrane by deposition of calcium. However, a significant involvement of the cardiovascular system was not detected in either of the cases.

In conclusion, despite the rarity of this pathology, one must be aware of the need for early diagnosis, recognizing the typical cutaneous manifestations of the disease, for adequate handling and better management of the associated complications when these are present, making periodical ophthalmologic and cardiovascular follow-ups imperative. 


\section{REFERENCES}

1. Chassaing N, Martin L, Calvas P, Le Bert M, Hovnanian A. Pseudoxanthoma elasticum: a clinical, pathophysiological and genetic update including 11 novel ABCC6 mutations. J Med Genet. 2005;42:881-92.

2. Finger RP, Charbel Issa P, Ladewig MS, Götting C, Szliska C, Scholl HP, et al. Pseudoxanthoma elasticum: genetics, clinical manifestations and therapeutic approaches. Surv Ophthalmol. 2009;54:272-85.

3. Li Q, Jiang $Q$, Pfendner E, Váradi A, Uitto J. Pseudoxanthoma elasticum: clinical phenotypes, molecular genetics and putative pathomechanisms. Exp Dermatol. 2009;18:1-11.

4. Li Q, Török L, Kocsis L, Uitto J. Mutation analysis (ABCC6) in a family with pseudoxanthoma elasticum: presymptomatic testing with prognostic implications. Br J Dermatol. 2010;163:641-3.

5. Bressan AL, Vasconcelos BN, Silva RS, Alves MFGS, Gripp AC. Periumbilical and periareolar perforating pseudoxanthoma elasticum. An Bras Dermatol. 2010;85:705-7.

6. Lee TK, Forooghian F, Cukras C, Wong WT, Chew EY, Meyerle CB. Complementary angiographic and autofluorescence findings in pseudoxanthoma elasticum. Int Ophthalmol. 2010;30:77-9.

7. Jiang Q, Endo M, Dibra F, Wang K, Uitto J. Pseudoxanthoma Elasticum is a Metabolic Disease. J Invest Dermatol. 2009;129:348-54.

8. Braun SA, Finis D, Helbig D. Pseudoxanthoma elasticum. More than a skin problem. Hautarzt. 2013;64:222, 224-5.

9. LaRusso J, Li Q, Uitto J. Pseudoxanthoma Elasticum, the Paradigm of Heritable Ectopic Mineralization Disorders - Can Diet Help? J Dtsch Dermatol Ges. 2011;9:586-93.

10. Marwah M, Godse K, Patil S, Nadkarni N, Gautam M. Surgical Correction of Pseudoxanthoma Elasticum. J Cutan Aesthet Surg. 2012;5:212-3.
MAILING ADDRESS:

Gabriela Franco Marques

Rua Alves Guimarães 518, ap. 136

05410-000 - Pinheiros - São Paulo - SP

Brazil

E-mail: gabriela_franco_@hotmail.com

How to cite this article: Nakandakari S, Coelho APCP, Nigro MHMF, Marques GF, Sabage J. Pseudoxanthoma elasticum: report of two cases. An Bras Dermatol. 2014;89(5):812-15. 